\title{
Nutrição e genética na ocorrência de pragas, inimigos naturais e ataque de minadoras em feijão comum (Phaseolus vulgaris)
}

\section{Nutrition and genetics in the occurrence of pests, natural enemies and attack leaf miner in common bean (Phaseolus vulgaris)}

\author{
Wilton Pires da Cruz ${ }^{1}$, Fabrício Henrique Moreira Salgado ${ }^{1}$, Diogenis Fontenele Ferreira \\ Júnior ${ }^{1}$ e Rodrigo Ribeiro Fidelis ${ }^{1 *}$
}

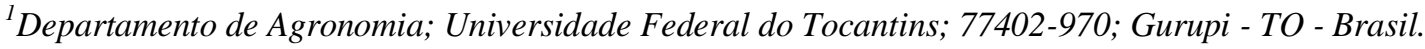

\begin{abstract}
The objective was to determine the occurrence of pests, ladybugs and the percentage of larvae mined attack common bean grown under deficient and adequate nitrogen. The study was conducted at the Federal University of Tocantins, in 12 genotypes of common bean under two managements of the element nitrogen $(N)$ (with and without stress). To collect samples of insects were made by tapping a meter per treatment in plastic traybefore and after application of insecticides. For the sampling of leaf miner were counted the number of leaves attacked by genotype. Found bug Nezara viridula, sharpshooter Empoaska spp., cows Cerotoma arcuata and Diabrotica speciosa, ladybugs Eriopis connexa and Cycloneda blood. There were no differences between the number of insect pests found in the bean with and without stress of $N$. The ladybug E. connexa was the one that occurred. Before applying insecticides to E. connexa occurred more under stress in plants of N. After insecticides E. connexa occurred more stress-free plants of $N$. The leaf miner attack was higher in plants without stress $N$. More leaves, the greater the percentage of miner attack in bean under stress of $N$.
\end{abstract}

Key-words: Nitrogen, plant defense, ladybug, leaf miner

\section{INTRODUÇÃO}

$\mathrm{Na}$ cultura do feijoeiro o nitrogênio é um dos macronutrientes mais absorvido (Oliveira e Fageria, 2003) e que devido ao ciclo curto da planta, é de fundamental importância que ele esteja à disposição para a planta em quantidade, tempo e local adequado (Soratto et al., 2005). Este nutriente estimula o crescimento vegetativo da planta, contribuindo assim que a mesma expresse todo o seu potencial produtivo. Entretanto o fator nutricional não influência apenas a produtividade, mas também a produção de metabólitos secundários (Gobbo-Neto e Lopes, 2007) necessários para a proteção da planta (Stintzi et al., 2001). Os metabólitos secundários representam uma interface química entre as plantas e o ambiente circundante, portanto, sua síntese é frequentemente afetada por condições ambientais (Kutchan, 2001). Outro fator importante no cultivo do feijoeiro é o controle de insetos que causam danos, além de serem vetores de diversas doenças, que geralmente é feito através de insumos químicos. A utilização de inseticidas é muito comum em cultivos de feijão em regiões tropicais. Problemas associados aos pesticidas usados no controle de pragas nos trópicos são: contaminação do ar (organofosforados); contaminação da água (organoclorados e organofosforados); contaminação do solo (organoclorados); formação de resistência das pragas contra os inseticidas;

Author for correspondence: fidelisrr@uft.edu.br 
eliminação dos inimigos naturais (produtos não seletivos); redução da população de polinizadores; redução da biodiversidade (Brechelt, 2004).

Entre as pragas que atacam a feijão comum estão a Cigarrinha-verde (Empoasca kraemeri), Vaquinhas (Diabrotica speciosa e Cerotoma arcuata), e adultos de Mosca-branca (Bemisia tabaci) (Pedigo e Rice, 2005). Outra importante praga é a mosca minadora Liriomyza spp. Os adultos da mosca-minadora são insetos pequenos, com aproximadamente $2,0 \mathrm{~mm}$ de comprimento, coloração preto-brilhosa com manchas amareloclara sobre o tórax, a fêmea realiza postura endofítica, isto é, deposita os ovos diretamente no parênquima foliar. Após poucos dias, a larva eclode e começa a se alimentar do tecido parenquimático, passando por três instares dentro da mina que forma na folha (Dantas, 2007). As moscas-minadoras são conhecidas mundialmente por atacar uma enorme quantidade de espécies vegetais, de ocorrência natural ou cultivados, das famílias Curcubitaceae, Leguminosae (Fabaceae) e Solanaceae. No Brasil, as moscas-minadoras atacam feijão, batata e tomate (Gallo et al., 2002).

São insipientes os estudos que relacionam a nutrição das plantas, o manejo de adubação, com dispersão e o percentual de área atacada por insetos ou ácaros pragas. Assim como a resistência de plantas em condições de estresse nutricional. Porém é possível encontrar trabalho sobre a resistência ao ataque de insetos de diferentes genótipos de soja, sob diferentes manejos de adubação (Lima e Lara, 2004). Quando uma planta é submetida a adubação não balanceada a tendência é apresentar maior ataque de pragas (Rodrigues e Cassino, 2003), com isso, uma dose de algum nutriente que ultrapasse ou esteja abaixo da exigência da planta pode influenciar determinantemente a proporção do ataque. Nestes nesse sentido, objetivou-se determinar a ocorrência de pragas, de Joaninhas (inimigos naturais) e o percentual de ataque de larvas minadoras em feijão comum, cultivado sob deficiente e adequada adubação nitrogenada.

\section{MATERIAL E MÉTODOS}

$\mathrm{O}$ estudo foi conduzido na Universidade Federal do Tocantins, Campus Universitário de GurupiTO, localizada a $11^{\circ} 43^{\prime} \mathrm{S}$ e $49^{\circ} 04^{\prime} \mathrm{W}$ e $280 \mathrm{~m}$ altitude. De acordo com a classificação de Köppen o clima é do tipo B1wA'a' úmido com moderada deficiência hídrica. $\mathrm{O}$ solo foi caracterizado como
Latossolo Vermelho-Amarelo distrófico, textura média segundo Embrapa (2006). A análise química e física do solo na camada de $0-20 \mathrm{~cm}$ mostrou os seguintes resultados: Pmel $1,1 \mathrm{mg} \cdot \mathrm{dm}^{-}$ 3; MO 2,0 \%; pH em $\mathrm{CaCl}_{2}$ 4,6; $\mathrm{Ca}+\mathrm{Mg}$ (5 cmol. $\left.\mathrm{dm}^{-3}\right), \mathrm{Ca}\left(3,6 \mathrm{cmol} \cdot \mathrm{dm}^{-3}\right), \mathrm{Mg}\left(1,4 \mathrm{cmol} . \mathrm{dm}^{-}\right.$ $\left.{ }^{3}\right), \mathrm{Al}\left(0,0 \mathrm{cmol} \cdot \mathrm{dm}^{-3}\right), \mathrm{H}+\mathrm{Al}\left(4,7 \mathrm{cmol} \cdot \mathrm{dm}^{-3}\right), \mathrm{K}$ $\left(0,1 \mathrm{cmol} \cdot \mathrm{dm}^{-3}\right)$, SB $\left(2,18 \mathrm{cmol} \cdot \mathrm{dm}^{-3}\right), \mathrm{V}(52,3 \%)$, Areia $\left(542,4\right.$ g. $\left.\mathrm{kg}^{-1}\right)$, silte $\left(54,9\right.$ g. $\left.\mathrm{kg}^{-1}\right)$ e argila $\left(402,7 \mathrm{~g} \cdot \mathrm{kg}^{-1}\right)$, não havendo necessidade de realização de calagem.

Utilizou-se o delineamento experimental de blocos completos casualizados com quatro repetições em esquema fatorial $2 \times 12$, dois ambientes (com e sem estresse de N) e 12 genótipos. Foram utilizados os cultivares de feijão comum, BRSRadiante, BRS-Grafite, Diamante Negro, BRSMarfim provenientes da Embrapa Arroz e Feijão, IAC-Una, IAC-Centauro, IAC-Diplomata, IACAlvorada provenientes do Instituto Agronômico de Campinas e IPR-Juriti, IPR-Colibri, IPR-Eldorado e IPR-139 provenientes do Instituto Agronômico do Paraná.

A parcela experimental foi constituída por quatro linhas de 4,0 m de comprimento, espaçadas de $0,45 \mathrm{~m}$. O plantio foi realizado visando obter um estande final de 12 plantas por metro linear, utilizando como área útil as duas linhas centrais. $\mathrm{O}$ trabalho foi constituído por dois ambientes um com estresse e outros sem estresse de nitrogênio.

A adubação de plantio foi igual para ambos os experimentos e foi realizada com base na analise do solo. Com base na recomendação aplicou-se no

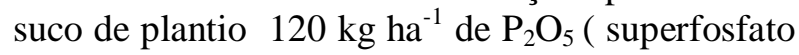
simples amoniacal com $3 \%$ de nitrogênio); $60 \mathrm{~kg}$ ha $^{-1}$ de $\mathrm{K}_{2} \mathrm{O}$ ( cloreto de potássio) e $20 \mathrm{~kg} \mathrm{ha}^{-1}$ de $\mathrm{N}$ proveniente do nitrogênio presente no superfosfato simples amônia. No experimento com estresse de nitrogênio não foi realizado adubação de cobertura. No experimento sem estresse, foi aplicado em cobertura $100 \mathrm{~kg} \mathrm{ha}^{-1}$ de nitrogênio na forma de uréia, parcelado em duas vezes, a primeira aos 15 e a segunda aos 30 dias após o plantio (DAP).

A semeadura do feijão foi realizada no dia 12 de junho na Entressafra de 2010. Foi realizado o tratamento de sementes com fungicida pertencente aos grupos químicos Benzimidazol e Dimetilditiocarbamato $(45+105 \mathrm{~g}$ i.a./100 kg de sementes) e inseticida pertencente ao grupo químico Pirazol (50 g i.a./100 kg de sementes). Durante a condução do experimento, a área foi mantida limpa com aplicação de herbicida 
pertencente ao grupo químico Oxima ciclohexanodiona e capina manual antes do florescimento (R6). O controle de insetos foi realizado com a aplicação de inseticida pertencente ao grupo químico Piretróide (4 g i.a./ha) aos 31 dias após a emergência (DAE) e inseticida pertencente ao grupo químico Organofosforado (500 g i.a./ha) 46 DAE.

A irrigação no experimento foi feita de acordo com as necessidades da cultura, seguindo recomendação para Santo Antônio de Goiás - GO (Curi e Campelo Júnior, 2001). Utilizou-se sistema por aspersão convencional com turno de rega de dois dias, tendo um período de funcionamento de duas horas. A vazão dos aspersores utilizados com pressão na base de $20 \mathrm{mca}$ propiciou lâmina d'água de 5,2 mm/hora.

A primeira amostragem dos insetos da parte aérea da planta foi realizada pela manhã no dia 31/07/2010, antes da aplicação de inseticidas. A segunda foi realizada pela manhã no terceiro dias após a aplicação dos inseticidas, no dia 07/08/2010. Para as amostragens, foi utilizado uma bandeja plástica branca de $0,005 \mathrm{~m}^{3}(30 \mathrm{~cm} \mathrm{x}$ $25 \mathrm{~cm} \times 7 \mathrm{~cm}$ ) para receptar os insetos, depois de bater os ramos do feijoeiro por 30 segundos contra a mesma. A parcela da amostragem utilizada foi um metro linear (12 plantas) escolhido ao acaso em cada repetição. Os insetos receptados na bandeja eram contabilizados em cada parcela.

A amostragem de folhas minadas no feijão foi realizado pela manhã no dia 07/08/2010. A parcela da amostragem utilizada foi um metro linear (12 plantas) escolhido ao acaso em cada repetição. Foi contabilizado o número de folhas com presença de minas em um metro linear por parcela. Em seguida foi contabilizada a quantidade de folhas em três plantas para estimar a média de folhas por plantas em um metro linear.

Os insetos coletados foram organizados por espécie e tratamento. Alguns dados foram transformados pela equação $(\sqrt{x+1})$ (Tabela $1 \mathrm{e}$ 2). Os dados médios foram submetidas a análise de variância e a comparação das médias foi realizada pelo teste de Tukey a 5\% de probabilidade. Também foi realizada análise de regressão linear simples, comparando se o número de folhas atacadas por larvas minadoras com o número médio de folhas por planta analisada, para constatar se há correlação entre estes dois fatores.

\section{RESULTADOS}

Das espécies de insetos que atacam o feijão, foram encontrados no cultivo em estudo, o percevejo Nezara viridula (Hemiptera: Pentatomidae), as vaquinhas Cerotoma arcuata e Diabrotica speciosa (Coleoptera: Chrysomelidae) e um complexo de cigarrinhas verdes Empoasca spp. (Hemiptera: Cicadellidae) (Tabela 1). Para o controle dessas pragas que ocorriam no cultivo foi realizado o controle preventivo com pesticidas. Pórem, anteriormente a essa aplicação, foram encontradas duas joaninhas, inimigos naturais importantes de pulgões (Hemiptera: Aphididae).

Tabela 1. Ocorrência, por metro linear, dos insetos fitófagos e de predadores na parte aérea de feijão (Phaseolus vulgaris), sob diferentes manejos de adubação nitrogenada, antes da aplicação de inseticidas. Gurupi, Tocantins, entressafra 2010.

\begin{tabular}{|c|c|c|c|c|c|c|}
\hline \multirow[b]{2}{*}{ Dose de $\mathrm{N}$} & \multicolumn{4}{|c|}{ Insetos-praga $\left(\mathrm{ml}^{-1}\right)$} & \multicolumn{2}{|c|}{ Inimigos naturais $\left(\mathrm{ml}^{-1}\right)$} \\
\hline & $\begin{array}{l}\text { Nezara } \\
\text { viridula }\end{array}$ & $\begin{array}{c}\text { Cerotoma } \\
\text { arcuata }\end{array}$ & $\begin{array}{c}\text { Diabrotica } \\
\text { speciosa }\end{array}$ & $\begin{array}{c}\text { Empoasca } \\
\text { spp. }\end{array}$ & $\begin{array}{l}\text { Cycloneda } \\
\text { sanguinea }\end{array}$ & $\begin{array}{c}\text { Eriopis } \\
\text { connexa }\end{array}$ \\
\hline Com & $1.05 \mathrm{a}^{*}$ & $1.02 \mathrm{a}$ & $1.02 \mathrm{a}$ & $1.00 \mathrm{a}$ & $1.01 \mathrm{a}$ & $1.50 \mathrm{a}$ \\
\hline Sem estresse & $1.08 \mathrm{a}$ & $1.02 \mathrm{a}$ & $1.02 \mathrm{a}$ & $1.02 \mathrm{a}$ & $1.01 \mathrm{a}$ & $1.14 \mathrm{~b}$ \\
\hline $\mathrm{CV}(\%)$ & 16.64 & 8.27 & 8.08 & 5.76 & 5.96 & 26.46 \\
\hline
\end{tabular}

*Médias seguidas de mesma letra nas colunas não se diferem estatisticamente pelo teste de Tukey a $5 \%$ de probabilidade.

As joaninhas Cycloneda sanguinea e a Eriopis connexa (Coleoptera: Coccinellidae), ocorreram nos dois períodos de coletas, antes e depois da aplicação dos inseticidas (Tabelas 1 e 2). Porém, E. connexa teve sua ocorrência estatisticamente maior no tratamento com baixas doses de nitrogênio, anteriormente a aplicação dos pesticidas (Tabela 1). Posteriormente às aplicações, essa joaninha foi mais abundante no tratamento com doses de nitrogênio recomendas para a cultura (Tabela 2). 
Tabela 2. Preferência de insetos predadores por plantas de feijoeiro quanto ao nível de adubação, após a aplicação de inseticidas. Gurupi, Tocantins, entressafra 2010.

\begin{tabular}{lcc}
\hline Doses de $\mathrm{N}$ & \multicolumn{2}{c}{ Inimigos naturais } \\
\hline Cycloneda sanguinea & Eriopis connexa \\
\hline Sem estresse & $1 \mathrm{a} *$ & $1,1 \mathrm{~b}$ \\
Com estresse & $1 \mathrm{a}$ & $1,2 \mathrm{a}$ \\
$\mathrm{cv}(\%)$ & 5.96 & 26.27 \\
\hline
\end{tabular}

* Médias seguidas de mesma letra na coluna não diferem pelo teste de Tukey a 5\% de probabilidade.

Logo após a aplicação dos inseticidas, a população das pragas foi controlada, porém, ocorreu também um decréscimo da população de inimigos naturais, principalmente, a joaninha E. connexa (Figura 1). O Percevejo verde foi o mais abundante entre as pragas. As vaquinhas $(C$. arcuata e $D$. speciosa) foram a segunda e a cigarrinha verde foi a terceira praga mais encontrada, utilizando-se a metodologia de batida de bandeja (Figura 1). A população de inimigos naturais (E. connexa) foi significativamente maior do que a de qualquer uma dessas pragas descritas anteriormente (Figura $1)$.

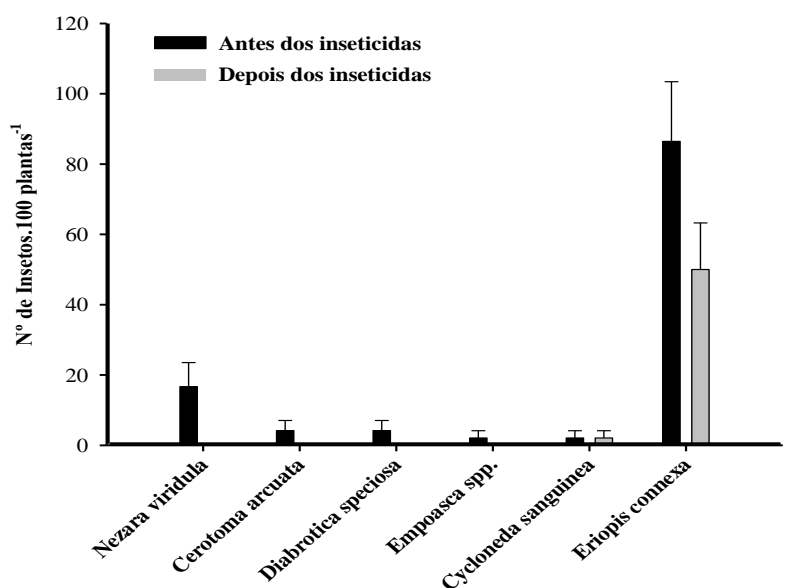

Figura 1- Número médio de Insetos ( \pm erro-padrão) por 100 plantas de feijão comum.

$\mathrm{O}$ ataque de larvas minadoras Liriomyza spp. (Diptera: Agromyzidae) no feijão foi maior quando na condição ideal de $\mathrm{N}$ para a cultura (Figura 2). O percentual de folhas atacada por planta foi, em torno, de seis nos genótipos cultivados sob estresse de N. Já nos genótipos cultivados sem estresse de $\mathrm{N}$, a média de folhas atacadas por planta foi, em torno, de oito (Figura 2).

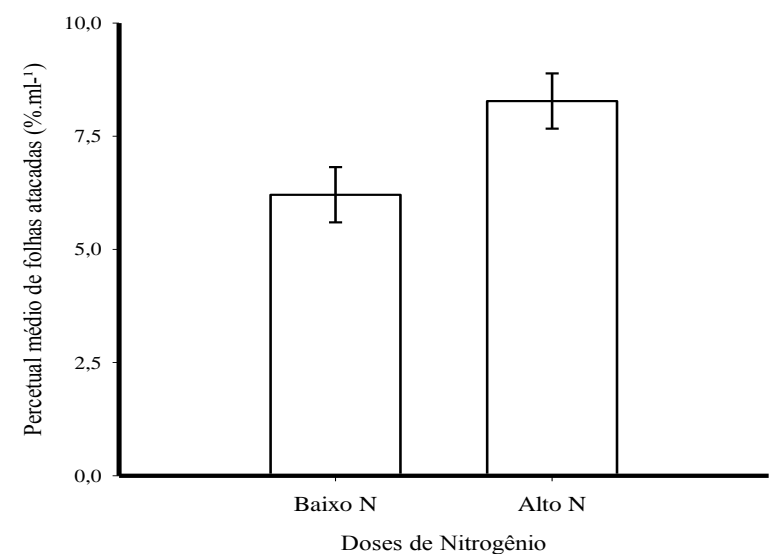

Figura 2 - Média percentual, por metro linear, de folhas atacadas por minadoras no feijão (Phaseolus vulgaris) sob alto $N$ (sem estresse) e baixo $N$ (com estresse), da adubação nitrogenada. A não sobreposição das barras de erro-padrão denota diferença estatística pelo teste de Tukey a $5 \%$ de probabilidade.

O número de folhas por plantas determinou o percentual de folhas atacadas, somente no tratamento com baixas doses de N. As plantas desse tratamento possuíam entre oito e 28 folhas por plantas. A análise de correlação linear mostrou que quanto mais folhas a planta possuía, mais folhas atacadas foram registradas, quando sob estresse de N (Figura 3). Na dosagem sem estresse de $\mathrm{N}$ para a cultura, não houve correlação entre $\mathrm{o}$ número de folhas por planta e o número de folhas atacadas por minadoras $(\mathrm{y}=5,586+0,0443 \mathrm{x}$; d.f.: 0,$317 ;$ p: 0,$577 ; r^{2}: 0,007 ; \mathrm{N}=43$ ). 


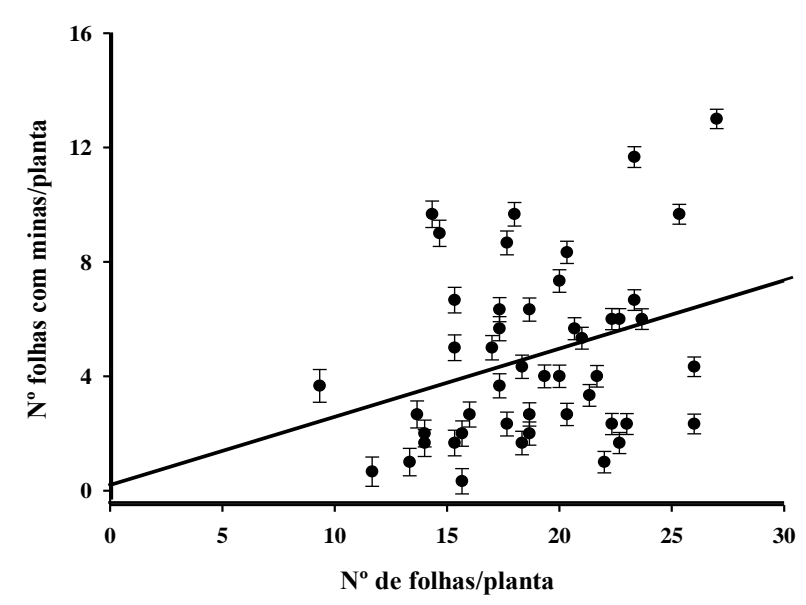

Figura 3 - Correlação entre o número médio de folhas por planta e o número média de folhas com presença de mina por planta ( \pm erro-padrão), no feijão comum cultivado em com estresse de $\mathrm{N}(\mathrm{y}=0,174+0,238 \mathrm{x}$; d.f.: 5,011; p: 0,03, $\mathrm{r}^{2}: 0,098, \mathrm{~N}=48$ ).
O número de folhas por plantas não variou significativamente entre os cultivares de feijão comum sob estresse de $\mathrm{N}$ e os que receberam doses recomendadas (sem estresse) (Tabela 3). No entanto, 66,6\% entre os genótipos cultivados sem estresse apresentaram mais folhas atacadas por minadoras do que os mesmos genótipos cultivados com estresse de N (Tabela 3). Os genótipos IACCentauro, IAC-Diplomata, IPR-Juriti e IPREldorado, foram os que, quando cultivados sob estresse de $\mathrm{N}$, apresentaram mais folhas atacadas por minadoras, do que quando cultivados sob dose adequada do nutriente (Tabela 3), não havendo diferença entre os ambientes para cada genótipo. Contudo, apenas os genótipos IPR-139 e BRSGrafite foram estatisticamente menos atacados sob condições de estresse nutricional, do que quando cultivados com a dose recomendada de $\mathrm{N}$ (Tabela 3).

Tabela 3. Percentual médio de folhas atacadas pela mosca minadora Liriomysa spp e número médio de folhas por planta, em diferentes genótipos de feijão comum (P. vulgaris), sob dois diferentes manejos nutricionais (Com e Sem estresse de N).

\begin{tabular}{cccccc}
\hline Genótipos & $\begin{array}{c}\text { Folhas atacadas } \\
\text { Com estresse }(\%)\end{array}$ & $\begin{array}{c}\text { Folhas atacada } \\
\text { Sem estresse }(\%)\end{array}$ & CV $(\%)$ & $\begin{array}{c}\text { Média de } \\
\text { folhas/Planta } \\
\text { (c/ estresse) }\end{array}$ & $\begin{array}{c}\text { Média de } \\
\text { folhas/Planta } \\
\text { (s/ estresse) }\end{array}$ \\
\hline BRS-Marfim & $3.45 \mathrm{a}^{*}$ & $5.28 \mathrm{a}$ & 38.55 & $17,58 \pm 2,91$ & $17,12 \pm 6,26$ \\
BRS-Radiante & $3.34 \mathrm{a}$ & $7.07 \mathrm{a}$ & 57.31 & $18,08 \pm 5,10$ & $20,16 \pm 7,44$ \\
BRS-Grafite & $4.50 \mathrm{~b}$ & $7.64 \mathrm{a}$ & 21.25 & $21,83 \pm 3,29$ & $16,38 \pm 3,66$ \\
Diamante Negro & $6.12 \mathrm{a}$ & $9.17 \mathrm{a}$ & 50.64 & $16,66 \pm 5,47$ & $21,85 \pm 2,79$ \\
IAC-Una & $4.03 \mathrm{a}$ & $12.81 \mathrm{a}$ & 71.12 & $17,41 \pm 2,53$ & $17,75 \pm 4,64$ \\
IAC-Centauro & $6.78 \mathrm{a}$ & $6.50 \mathrm{a}$ & 16.73 & $18,83 \pm 1,37$ & $15,74 \pm 4,79$ \\
IAC-Diplomata & $9.03 \mathrm{a}$ & $8.89 \mathrm{a}$ & 77.40 & $20,83 \pm 5,20$ & $18,66 \pm 4,96$ \\
IAC-Alvorada & $5.39 \mathrm{a}$ & $5.92 \mathrm{a}$ & 18.07 & $21,33 \pm 4,20$ & $24,16 \pm 4,30$ \\
IPR-Juriti & $7.07 \mathrm{a}$ & $6.42 \mathrm{a}$ & 51.89 & $18,58 \pm 5,68$ & $28,50 \pm 8,56$ \\
IPR-Colibri & $9.19 \mathrm{a}$ & $12.87 \mathrm{a}$ & 98.03 & $14,83 \pm 1,03$ & $13,83 \pm 2,68$ \\
IPR-Eldorado & $11.31 \mathrm{a}$ & $9.24 \mathrm{a}$ & 25.86 & $18,75 \pm 3,61$ & $17,87 \pm 1,50$ \\
IPR-139 & $4.30 \mathrm{~b}$ & $7.44 \mathrm{a}$ & 21.91 & $22,16 \pm 0,96$ & $21,75 \pm 5,22$ \\
\hline
\end{tabular}

* Médias seguidas de mesma letra na linha não se diferem estatisticamente pelo teste de Tukey a 5\% de probabilidade.

\section{DISCUSSÃO}

As populações dos insetos-praga encontrados em ambos os tratamentos (dose recomendada e baixa de N), foi igual (Tabela 1). Diferentemente do observado com o potássio, em que, sua deficiência caracteriza a maior infestação por insetos-praga em diversas culturas (Marschner, 1998), entretanto, a relação entre adubação nitrogenada e essas pragas são mais complexas. A deficiência nutricional gerada pela subdosagem de $\mathrm{N}$ no feijão favorece a redução na produção de compostos secundários, que agem como defesas naturais das plantas, principalmente os nitrogenados (GobboNeto e Lopes, 2007). Nessas condições a concentração de insetos-praga deveriam ser maiores do que em condições ideais de N. No entanto, um indicador de absorção de maiores concentrações de $\mathrm{N}$ é a prolina (Sánchez et al., 2007), quanto mais dessa proteína é encontrada nas plantas, pressupõe-se que ocorreu uma maior absorção de nitrogênio , essa proteína liga-se aos compostos secundários das plantas (taninos), eliminando seu efeito tóxico (Oliveira e Berchielli, 2007). Portanto, boa nutrição da planta com 
nitrogênio, isoladamente, ainda não garante menor ocorrência de pragas. $\mathrm{O}$ nitrogênio vai favorecer a produção de prolina, que os insetos herbívoros poderiam utilizar, para neutralizar taninos produzidos pelas plantas para própria defesa.

As pragas encontradas nesse experimento, também estiveram entre as mais abundantes em cultivo experimental de feijão comum em Viçosa-MG (Fernandes et al., 2010). Fernandes et al. (2010) encontraram 13 diferentes espécies de inimigos naturais associados ao feijão comum, estando, entre eles, as joaninhas $C$. sanguinea e $E$. connexa. As joaninhas são predadoras, principalmente, de pulgões, mas que também predam ácaros (Arthropoda: Acari), Tripes (Thysanoptera) e ovos de lepdópteros (Isikber e Copland, 2002; Sarmento et al., 2007). A joaninha E. connexa foi mais abundante do que $C$. sanguinea (Tabela 1 e 2; Figura 1), nesse experimento. Eriopis connexa apresenta correlação positiva com a densidade populacional da cigarrinha-verde (E. kraemeri) (Fernandes et al., 2010). A ocorrência de cigarrinhas-verde pode explicar a maior abundância de E. connexa, nesse sistema.

A significativa preferência de E. connexa pelas plantas do tratamento com baixa dose de $\mathrm{N}$ pode ser explicada pela maior ocorrência de ácaros, tripes ou ovos de lepdópteros, cuja detecção não foi possível devido a metodologia utilizada. Após a aplicação de inseticidas, a ocorrência em maior quantidade nas plantas que receberam adequada dosagem de N, da joaninha E. connexa, deu-se, provavelmente, pela busca por abrigo promovido por estas plantas. As plantas que obtiveram adequada nutrição apresentavam folhas com a cor mais escura e com maior área foliar (observação de campo), promovendo maior cobertura do solo. Predadores associados a plantas mantêm-se por mais tempo nestas, quando encontram abrigo na estrutura vegetal (Cortesero et al., 2000; Altieri et al., 2003).

Inseticidas químicos, conhecidamente, têm efeitos nocivos sobre inimigos naturais. Mesmo os chamados naturais, como os provenientes da planta neem (ou nim) (Azadirachta indica), cujo princípio ativo é Azadiractina, que provoca mortalidade de pelo menos $12,5 \%$, redução da capacidade de predação e drástica redução do numero de ovos postos e de posturas da joaninha E. connexa (Ribeiro et al., 2009). Esses efeitos podem ser somados a efeitos ambientais e para a saúde das pessoas envolvidas na aplicação, no caso dos inseticidas não naturais utilizados nesse trabalho (organofosforado e deltametrina). Essa afirmativa reforça a suposição acima, de que a joaninha buscou abrigo dos inseticidas nas plantas que garantiam mais proteção contra os inseticidas aplicados. Como pode ser observado na figura 1, os inseticidas, num prazo curto, controlam a população das pragas, porém afeta diretamente os inimigos naturais analisados, sem falar de efeitos indiretos na reprodução e capacidade de predação destes, que não é abordado neste trabalho.

As características positivas, acima citadas pertencentes às plantas nutridas adequadamente com N (coloração mais escura e maior área foliar), aparentemente, são fatores que explicariam a preferência do ataque da mosca minadora Liriomyza spp.. Por alimentarem-se do mesófilo foliar, essa praga irá certamente selecionar plantas que possuírem esta estrutura mais bem desenvolvida. A concentração de recursos promovida pela adequada nutrição nitrogenada, faz, como o exposto acima, com que haja maior cobertura do solo, favorecendo a preferência das pragas, essa é outra possível explicação para a preferência das moscas minadoras (Ritchie e Olff, 1999). Outro fato é a dificuldade encontrada pelos inimigos naturais, para localizarem as larvas minadoras, devido a maior cobertura de área promovidas pelas plantas mais bem nutridas. Um dos principais inimigos naturais dessa espécie de praga é o parasitóide Opius sp. (Hymenoptera: Braconidae), que controla as larvas, que são os que causam os danos (Santos et al., 2008). Estes parasitóides utilizam as larvas como hospedeiras das suas progênies, ao ovipositar no interior destas, para que a larva do parasitóide possa alimentar-se do conteúdo interno da lagarta, emergindo, posteriormente, um ou mais adultos. Quando as larvas estão mais expostas esses parasitóides podem encontrar com mais facilidade as larvas minadoras, resultando em menos gasto de energia (Barrette et al., 2010).

A preferência da mosca minadora por plantas com maior número de folhas, no feijão cultivado sob estresse de $\mathrm{N}$, deu-se pela maior concentração de recurso de mais qualidade. Todavia, maior número de folhas significa mais alimentos que poderiam ser explorados pelas larvas minadoras. Ou ainda, que as plantas que produziam mais folhas, apresentavam maior eficiência na absorção de nitrogênio, fornecido em baixa quantidade, e, com isso, apresentariam maior qualidade da biomassa. A relação, portanto, entre a qualidade e a quantidade de alimento disponível, determina a 
maior ou menor intensidade de ataque da larva minadora.

Os genótipos IPR-139 e BRS-Grafite foram os mais eficientes e os que apresentaram as melhores respostas à adubação com nitrogênio, quando cultivados sob estresse, produziram $1000 \mathrm{~kg} \mathrm{ha}^{-1}$ de feijão, enquanto que sob adequada nutrição, produziram $2.500 \mathrm{~kg}$ há $^{-1}$ (Salgado, 2011). Esses genótipos foram, portanto, os que menos sofreram com a deficiência de N, entre os 12 avaliados. Essa condição pode significar que a produção de compostos secundários que servem de defesa contra o ataque de pragas, tenha sido adequada, desencorajando as moscas minadoras a escolherem esses genótipos. Por outro lado, o genótipo BRS Marfim, foi o menos preferido pela mosca minadora, para os dois tratamentos. Nesse caso, características intrínsecas, como por exemplo, menor espessura do mesófilo foliar ou impedimento mecânico na superfície foliar pela maior absorção de silício, ou seja, algumas constituições genotípicas favoráveis, que possivelmente possui esse genótipo, fazem com que este seja menos danificado que os outros analisados, conferindo the mais resistência que os demais a mosca minadora (Rosseto, 1973).

\section{CONCLUSÕES}

A adubação adequada de nitrogênio em feijão comum não confere a este menos preferência das pragas dessa cultura, nos genótipos analisadas nesse trabalho. A joaninha E. connexa foi o predador mais abundante em feijão comum, na região de cerrado estudada. A mosca minadora Liriomyza spp. tem preferência pelos genótipos cultivados com dose recomendada de nitrogênio. Em relação ao feijão cultivado sob estresse nutricional, a mosca minadora tem preferência pelos que apresentam maior número de folhas. Os genótipos IPR-139 e BRS-Grafite foram mais atacados pela mosca minadora quando cultivados sob dose adequada de N. O genótipo BRS-Marfim é o mais resistente à mosca minadora, entre os 12 genótipos avaliados.

\section{RESUMO}

Objetivou-se determinar a ocorrência de pragas, joaninhas e o percentual de ataque de larvas minadoras em feijoeiro-comum, cultivado sob deficiente e adequada adubação nitrogenada. $\mathrm{O}$ estudo foi conduzido na Universidade Federal do Tocantins, em 12 genótipos de feijoeiro-comum, sob dois manejos do elemento Nitrogênio (N) (com e sem estresse). Para a coleta dos insetos foram feitas amostragens com batidas de um metro linear por tratamento em bandeja plástica, antes e depois da aplicação de inseticidas. Para a amostragem das moscas minadoras foram contabilizadas o número de folhas atacadas por genótipo. Foram encontrados percevejo Nezara viridula, cigarrinha Empoaska spp., vaquinhas Cerotoma arcuata e Diabrotica speciosa, joaninhas Cycloneda sanguinea e Eriopis connexa. Não houve diferenças entre o número de insetos pragas encontrados no feijoeiro com e sem estresse de N. A joaninha E. connexa foi a de maior prevalência. Antes da aplicação de inseticidas a $E$. connexa ocorreu mais nas plantas sob estresse de N. Após os inseticidas a $E$. connexa ocorreu mais nas plantas sem estresse de N. O ataque de moscas minadoras foi maior em plantas sem estresse de N. Maior número de folhas, maior o percentual de ataque de minadora em feijoeiro sob estresse de N.

Palavras-chave: Nitrogênio, defesa da planta, joaninha, mosca minadoras

\section{REFERÊNCIAS}

Altieri, M. A.; Silva, N. E. Nicholls, C. I. (2003), O papel da biodiversidade no manejo de pragas. 1 Ed., Ribeirão Preto, Holos, 226p.

Barrette, M.; Boivin, G.; Brodeur, J. Giraldeau, L. A. (2010), Travel time affects optimal diets in depleting patches. Behavioral Ecology and Sociobiology, 6, 593-598.

Brechelt, A. (2004), Manejo ecológico de pragas e doenças. Rede de Ação em Praguicidas e suas Alternativas para a América Latina (RAP-AL): Santiago de Chile, 33p.

Cortesero, A. M.; Stapel, J. O. Lewis, W. J. (2000), Understanding and manipulating plant attributes to enhance biological control. Biological Control, 17, 35-49.

Dantas, D. J. Avaliação de híbridos de melão cantaloupe. Dissertação (Mestrado em Agronomia) - Universidade Federal Rural do Semi-Árido, 2007.

EMPRESA BRASILEIRA DE PESQUISA AGROPECUÁRIA - EMBRAPA (2006). Centro nacional de pesquisa de solos. Sistema brasileiro de classificação de solos. 2 Ed., Rio de Janeiro, Embrapa, 306p. 
Fernandes, F. L.; Picanço, M. C.; Fernandes, M. L. S.; Xavier, V. M.; Martins, J. C. Silva, V. F. (2010), Controle biológico natural e interações ecológicas com predadores e parasitóides em feijoeiro. Bioscience Journal, 26, 6-14.

Gallo, D.; Nakano, O.; Silveira-Neto, S.; Carvalho, R. P. L.; Baptista, G. C.; Berti-Filho, E.; Parra, J. R. P.; Zucchi, R. A.; Alves, S. B.; Vendramim, J. D.; Marchini, L. C.; Lopes, J. R. S. Omoto, C. (2002). Entomologia agrícola. 1 Ed., Piracicaba, Fealq, 920p.

Gobbo-Neto, L. Lopes, N. P. (2007), Plantas medicinais: fatores de influência no conteúdo metabólitos secundários. Quimíca Nova, 30, 374381.

Isikber, A. A. Copland, M. J. W. (2002), Effects of various aphid foods on Cycloneda sanguinea. Entomologia Experimentalis et Applicata, 102, 93 97.

Kutchan, T. M. (2001), Ecological arsenal and developmental dispatcher: the paradigm of secondary metabolism. Plant Physiology, 125, 5860 .

Lima, A. C. S. e Lara, F. M. (2004), Resistência de Genótipos de Soja à Mosca Branca Bemisia tabaci (Genn.) Biótipo B (Hemiptera: Aleyrodidae). Neotropical Entomology, 33, 71-75.

Marschner, H. (1998). Mineral nutrition of higher plants. 2.ed. Academic Press., 889p.

Oliveira, S. G. e Berchielli, T. T. (2007), Potencialidades da utilização de taninos na conservação de forragens e nutrição de ruminantes- revisão. Archives of Veterinary Science, 12, 1-9.

Oliveira, I. P. de Fageria, N. K. (2003), Calagem e Adubação. In: Moreira, J.A.A.; Stone, L. f. and Biava, M. Feijão: o produtor pergunta a Embrapa responde. 1. ed. Brasilia, Embrapa Informação Tecnológica 39-53p.

Pedigo, L. P. e Rice, M. E. (2005), Entomology and pest management. Prentice Hall: New Jersey, $784 \mathrm{p}$.
Ribeiro, L. P.; Dequech, S. T. B.; Rigo, D. S.; Ferreira, F.; Sausen, C. D.; Sturza, V. S. Camera, C. (2009), Toxicidade de inseticidas botânicos sobre Eriopis connexa (Coleoptera: Coccinellidae). Uruguaiana, 16, 246-254.

Richie, M. E. e Olff, H. (1999), Spatial scaling laws yield a synthetic theory of biodiversity. Nature, 400, 557-560.

Rodrigues, W. C. e Cassino, P. C. R. (2003), Efeito da adubação nitrogenada e potássica sobre a população de Aleurothrixus floccosus (Homoptero: Aleyrodidae), em laranja doce (Citrus sinensis) cv. Folha Murcha. Revista Universidade Rural, Série Ciências da Vida, 22, 55-59.

Rosseto, C. J. (1973), Resistência de plantas a insetos. Piracicaba, ESALQ, 171p.

Salgado, F. H. M. Efeito do nitrogênio na produtividade de grãos e qualidade fisiológica de sementes de genótipos de feijão comum. Dissertação (Mestrado em Produção Vegetal) Universidade Federal do Tocantins, 2011.

Sánchez, E.; Ávila-Quezada, G.; Dardea, A. A.; Ruiz, J. M. Romero, L. (2007), Biosynthesis of proline in fruits of green bean plants: deficiency versus toxicity of nitrogen. Revista Internacional de Botânica Experimental, 76, 143-152.

Santos, J. P.; Dal Soglio, F. K.; Redaelli, L. R. Foelkel, E. (2008), Levantamento e identificação de parasitóides de dípteros minadores em plantas de crescimento espontâneo em pomar orgânico de citros em Montenegro-RS, Brasil. Arquivos do Instituto Biológico, 75, 313-319.

Sarmento, R. A.; Venzon, M.; Pallini, A.; Oliveira, E. E. Arne, J. (2007), Use of odours by Cycloneda sanguinea to assess patch quality. Entomologia Experimentalis et Applicata, 124, 313-318.

Soratto, R. P; Crusciol, C. A. C.; Silva, L. M. Lemos, L. B. (2005), Aplicação tardia de nitrogênio no feijoeiro em sistema de plantio direto. Bragantia, 64, 211-218

Stintzi, A.; Weber, H.; Reymond, P.; Browse, J. Farmer, E. E. (2001), Plant defense in the absence of jasmonic acid: the role of cyclopentenones. PNAS, 98, 12.837-12.842. 